NIV naïve initially, $13 \%$ went home established on NIV. Survival at 365 days post procedure was 64\%. Subset analysis of outcomes in bulbar vs. non-bulbar MND, FVC $<$ or $>50 \%$ and NIV for procedure only vs. discharge with NIV has not shown any statistically significant differences, although absolute numbers are small.

Conclusions High risk NMD patients can have PEGs inserted safely. Our complications and one year survival rates are better compared with current published evidence in lower risk groups. We believe this is due to intensive support and monitoring during the procedure and use of NIV. Although survival is largely related to disease progression, further analysis is required with larger numbers to fully assess the impact of PEG feeding on it.

\section{P178 NOCTURNAL OXIMETRY MONITORING TO PREDICT HYPERCAPNIA IN OBESE PATIENTS}

${ }^{1} S$ Mandal, ${ }^{1} E$ Suh, ${ }^{1} \mathrm{M}$ Kamalanathan, ${ }^{1} \mathrm{M}$ Ramsay, ${ }^{1} \mathrm{R}$ Harding, ${ }^{2} \mathrm{~J}$ Moxham, ${ }^{1} \mathrm{~N}$ Hart; ${ }^{1}$ Lane Fox Respiratory Clinical Respiratory Physiology Research Centre, Guy's, St Thomas' NHS Foundation Trust, London, UK; 'Division of Asthma, Allergy and Lung Biology, King's College London, London, UK

\subsection{6/thoraxjnl-2013-204457.330}

Introduction Clinical commissioning standards have been developed to streamline clinical pathways. It is now common practice for obese patients with suspected sleep disordered breathing to undergo nocturnal oximetry monitoring prior to the clinic consultation. Although this test is useful for diagnosis and risk stratification of patients, there are limited data reporting the use of oximetry to predict hypercapnia. We hypothesised that overnight oxygen saturations could be used to predict hypercapnia.

Method 186 oximetry studies from patients with a body mass index (BMI) $>30 \mathrm{~kg} \cdot \mathrm{m}^{-2}$ and an $\mathrm{FEV}_{1} / \mathrm{FVC}>0.7$ were analysed, including the percentage of total analysis time spent with an oxygen saturation $\left(\mathrm{S}_{\mathrm{p}} \mathrm{O}_{2}\right)$ below $90 \%(\mathrm{~T}<90 \%), 80 \%(\mathrm{~T}<$ $80 \%)$ and $70 \%(\mathrm{~T}<70 \%)$ as well as $4 \%$ and $3 \%$ oxygen desaturation index (ODI). Correlations and linear regression analyses were performed to determine the variables that predicted a daytime arterial partial pressure of carbon dioxide $\left(\mathrm{P}_{\mathrm{a}} \mathrm{CO}_{2}\right)>6.0$ $\mathrm{kPa}$. Binary logistic regression and receiver-operator characteristic analyses assessed the utility of these parameters in predicting hypercapnia.

Results Compared to the eucapnic group the hypercapnic patients had a higher 4\% ODI (42.6 \pm 35.5 events/hour vs. $24.5 \pm 19.5$ events/hour, $\mathrm{p}=0.003)$, lower mean $\mathrm{SpO}_{2}$ $(89.0 \pm 7.4 \%$ vs. $94.1 \pm 3.2 \% \mathrm{p}=\mathrm{ns})$ and higher $\mathrm{T}<90 \%$ $(36.3 \pm 32.1 \%$ vs. $13.5 \pm 20.4 \%, \mathrm{p}<0.001)$.

Significant, albeit weak, correlations between $\mathrm{PaCO}_{2}$ and $4 \%$ ODI, 3\% ODI, $\mathrm{T}<90 \%, \mathrm{~T}<80 \%, \mathrm{~T}<70 \%$ were observed (Table 1 ). Only $\mathrm{T}<90 \%$ was predictive of hypercapnia. Using the total analysis time with an $\mathrm{S}_{\mathrm{p}} \mathrm{O}_{2}<90 \%$, a cut off level of $\geq 7.2 \%$ had a sensitivity of $80 \%$ and a specificity of $60 \%$ in predicting a $\mathrm{PaCO}_{2}>6 \mathrm{kPa}$, area under the curve was 0.76 .

Conclusion The proportion of time spent with an $\mathrm{S}_{\mathrm{p}} \mathrm{O}_{2}<90 \%$ predicted hypercapnia in obese patients. This has the potential to risk stratify patients, optimising both the timing and type of treatment delivered, which in turn will enhance the delivery of care. Specifically, this would facilitate clinical decision making in directing patients towards investigation for receiving non-invasive ventilation rather than continuous positive airway pressure therapy if hypercapnia were predicted from the proportion of the time with an $\mathrm{S}_{\mathrm{p}} \mathrm{O}_{2}<90 \%$.

\section{P179 FORCED VITAL CAPACITY, SYSTEMIC INFLAMMATION AND CARDIOMETABOLIC MARKERS IN ADULTHOOD: A CROSS-SECTIONAL ANALYSIS}

${ }^{1} \mathrm{NJ}$ Saad, ${ }^{2} \mathrm{M}$ Kaakinen, ${ }^{3} \mathrm{~A}$ Da Silva Couto Alves, ${ }^{1} \mathrm{C}$ Minelli, ${ }^{4} \mathrm{MR}$ Jarvelin, ${ }^{1} \mathrm{PGJ}$ Burney; ${ }^{1}$ Respiratory Epidemiology and Public Health Group, National Heart and Lung Institute, Imperial College London, London, United Kingdom; ${ }^{2}$ Institute of Health Sciences and Biocenter Oulu, University of Oulu, Oulu, Finland; ${ }^{3}$ Department of Epidemiology and Biostatistics, MRC Health Protection Agency (HPA) Centre for Environment and Health, School of Public Health, Imperial College London, London, United Kingdom; ${ }^{4}$ Department of Epidemiology and Biostatistics, MRC Health Protection Agency (HPA) Centre for Environment and Health, School of Public Health, Imperial College London and Unit of Primary Care, Oulu University Hospital, Oulu and London, United Kingdom and Finland

\subsection{6/thoraxjnl-2013-204457.331}

Introduction Forced vital capacity (FVC) is a powerful predictor of mortality, more than airflow obstruction (Burney et al. Thorax 2011;66:49-54). FVC is associated with systemic inflammation as well as with cardiovascular disease and diabetes. Given that systemic inflammation is also associated with cardiovascular disease and diabetes, systemic inflammation could explain the observed association between FVC and cardiometabolic markers. Here, we examined the association between FVC, cardiometabolic markers and systemic inflammation in 3,731 individuals belonging to the Northern Finland Birth Cohort 1966.

Methods Using linear regression, we examined the association between i) cardiometabolic markers (systolic blood pressure, diastolic blood pressure, LDL cholesterol, triglycerides, fasting glucose, insulin and HOMA-IR) and inflammatory markers (Creactive protein (CRP) and white blood cell count (WBC)), ii) FVC and inflammatory markers, and iii) FVC and cardiometabolic markers. We then tested whether the association between FVC and cardiometabolic markers could be explained by systemic inflammation, by adjusting the linear regression models of FVC on each cardiometabolic marker for the two inflammatory markers.

Results Increasing levels of inflammatory markers were associated with a decrease in FVC, $-12 \mathrm{~mL}$ per $\mathrm{mg} / \mathrm{L}$ of CRP $(95 \%$ confidence interval $(\mathrm{CI}):-17$ to $-7 \mathrm{~mL}$ ) and $-17 \mathrm{~mL}$ per $10^{9}$ cells/L of WBC (95\% CI: -28 to $-7 \mathrm{~mL}$ ), and with increasing levels of the cardiometabolic markers. FVC also decreased with

\begin{tabular}{|c|c|c|}
\hline \multirow[b]{3}{*}{ Cardiometabolic markers } & \multicolumn{2}{|l|}{$\mathrm{FVC}(\mathrm{mL})$} \\
\hline & $\begin{array}{l}\text { Unadjusted } \\
\text { analysis }^{\mathrm{a}}\end{array}$ & $\begin{array}{l}\text { Analysis adjusted } \\
\text { for systemic } \\
\text { inflammation }^{b}\end{array}$ \\
\hline & beta $(95 \% \mathrm{Cl})$ & beta $(95 \% \mathrm{Cl})$ \\
\hline Systolic blood pressure (SD=13.6mmHg) & $-27(-45 ;-8.1)^{\star *}$ & $-21(-40 ;-2.9)^{*}$ \\
\hline Diastolic blood pressure (SD=11.4mmHg) & $-60(-78 ;-43)^{* * *}$ & $-57(-75 ;-40)^{* * *}$ \\
\hline LDL Cholesterol $(S D=0.88 \mathrm{mmol} / \mathrm{L})$ & $-31(-49 ;-13)^{* \star}$ & $-30(-48 ;-13)^{\star \star}$ \\
\hline Triglycerides $(S \mathrm{~S}=0.73 \mathrm{mmol} / \mathrm{L})$ & $-74(-91 ;-56)^{* * *}$ & $-68(-86 ;-50)^{* * *}$ \\
\hline Glucose $(S D=0.58 \mathrm{mmol} / \mathrm{L})$ & $-26(-44 ;-8.8)^{\star *}$ & $-25(-42 ;-7.2)^{\star *}$ \\
\hline Insulin (SD=4.3mU/L) & $-74(-91 ;-57)^{* * *}$ & $-68(-85 ;-50)^{\star * *}$ \\
\hline HOMA-IR & $-61(-75 ;-46)^{\star * *}$ & $-55(-70 ;-40)^{\star \star *}$ \\
\hline \multicolumn{3}{|c|}{$\begin{array}{l}{ }^{a} \text { Adjusted for height at } 31 \text { years and gender. }{ }^{b} \text { Adjusted for height, gender, } C \text {-reactive pro- } \\
\text { tein and white blood cell count, measured at } 31 \text { years. Except for HOMA-IR, associations } \\
\text { are reported as regression coefficients (beta) per standard deviation (SD) change in the car- } \\
\text { diometabolic marker, with } 95 \% \text { confidence interval }\left(95 \% \text { CI). }{ }^{*} P<0.05,{ }^{* * P}<0.01,{ }^{* * * P}\right. \\
<0.001 \text {. }\end{array}$} \\
\hline
\end{tabular}


increasing levels of cardiometabolic markers (Table, column 1) and adjusting these associations for the inflammatory markers did not substantially alter them (Table, column 2).

Conclusion The association between FVC and cardiometabolic markers is not explained by variation in inflammatory markers, as measured by CRP and WBC. However, due to the cross-sectional nature of the analysis, no inference can be made with regard to the directionality of the associations.

\section{P180 NOCTURNAL OXIMETRY IN CYSTIC FIBROSIS (CF)}

E Stockley, N Patel, M Rosenthal, HI Tan; Royal Brompton Hospital, London, UK

\subsection{6/thoraxjn-2013-204457.332}

Background It is common for CF children in the UK to receive sleep-disrupting 4 hourly observations day and night throughout their hospital stays for intravenous antibiotics or exacerbations judging from parental and patient feedback. As oxygen desaturations occur mainly during REM sleep rather than NREM sleep, these desaturations could be missed by the intermittently performed "routine observations". Our unit performs nocturnal oximetry studies on night 1 of admission for all CF patients admitted for intravenous antibiotics and discontinues them if oxygenation is normal and the patient improving.

Aims To determine whether day time physiology or lab work is predictive of nocturnal hypoxaemia.

Methods A retrospective comparison of nocturnal oximetry studies and daytime physiology plus HbA1c of all CF patients admitted for intravenous antibiotics between January and June 2013.

Results 54 CF patients were admitted, with 19/54 elective and $35 / 54$ acutely. Table 1 summarises the clinical characteristics and nocturnal oximetry results of the patients. There was a weak positive correlation between Mean SpO2 and admission FEV1 $\left(\mathrm{p}=0.0012, \mathrm{r}^{2}=0.21\right)$ and admission FVC $(\mathrm{p}=0.0024$, $\left.\mathrm{r}^{2}=0.18\right)$. Nocturnal oxygen was commenced in $4 / 54$ children $(7.4 \%)$ as their mean $\mathrm{SpO} 2$ was $<93 \%$. All of them had an FVC $<60 \%$, the only ones in the cohort. 3 of the children improved (FVC improved to $71 \%, 75 \%$ and $87 \%$ from $44 \%$, $54 \%$ and $58 \%$ respectively), they were weaned off oxygen before discharge, with normal gas exchange on repeat nocturnal oximetry) and 1 died.
Abstract P180 Table 1. Nocturnal oximetry in Cystic Fibrosis (CF).

\begin{tabular}{ll}
\hline Age (years) & $13[0.11-17.5]$ median[range] \\
Admission FEV1 (\% predicted) & $75[69-80]$ mean[ $95 \% \mathrm{Cl}]$ \\
Admission FVC (\% predicted) & $85[80-90]$ mean[95\%Cl] \\
Best FEV1 in past year (\% predicted) & $88[83-92]$ mean[ $[95 \% \mathrm{Cl}]$ \\
Best FVC in past year (\% predicted) & $97[94-101]$ mean[95\%Cl] \\
Mean Sp02 (\%) & $97.1[91.4-98.9]$ median[range] \\
Desaturations $\geq 4 \% /$ hour & $1.5[0-10.05]$ median[range] \\
Percentage time sats $<90 \%$ & $0[0-10.9]$ median[range] \\
HbA1C $(\%)$ & $5.7[4.2-7.1]$ median[range] \\
\hline
\end{tabular}

Conclusion Patients with an admission FVC of $<60 \%$ warrant close monitoring for nocturnal hypoxaemia. In CF patients who are cardiovascularly stable, performing an oximetry study on first night of admission may be a less disruptive alternative to routine intermittent observations nightly for the whole duration of the admission.

\section{P181 TRANSCUTANEOUS CO2 MONITORING IN HYPERCAPNOEIC RESPIRATORY FAILURE: A META-ANALYSIS OF PROSPECTIVE STUDIES}

J Van Oppen, P Thiagarajan, A Khanna, M Sovani; Nottingham University Hospitals NHS Trust, Nottingham, United Kingdom

\subsection{6/thoraxjnl-2013-204457.333}

Introduction The role of transcutaneous carbon dioxide monitoring $\left(\mathrm{P}_{\mathrm{tc}} \mathrm{CO}_{2}\right)$ for patients with respiratory failure has been studied in a variety of clinical settings. However, its accuracy compared to arterial partial pressure of carbon dioxide $\left(\mathrm{PaCO}_{2}\right)$ in patients undergoing non-invasive ventilation (NIV) for hypercapnoeic respiratory failure has not been validated. The degree to which $\mathrm{PtcCO}_{2}$ approximates 'gold-standard' $\mathrm{PaCO}_{2}$ in this context was evaluated in a meta-analysis including 16 prospective observational studies.

Methods 16 prospective studies evaluating $\mathrm{PtcCO}_{2}$ as a correlate for $\mathrm{PaCO}_{2}$ in patient cohorts undergoing NIV were included. In all cases, Bland-Altman analysis was used to compare agreement among measures. Mean bias between the two methods of

\section{Abstract P181 Table 1.}

\begin{tabular}{|c|c|c|c|c|}
\hline Study & Type & $\mathrm{N}$ & Time & Mean bias/2SD \\
\hline Berkenbosch et al (2001) & Paediatric trauma, ARDS & 25 & 4 Hours & $0.02(3.27)$ \\
\hline Chakravarthy et al (2010) & Ventilator weaning in cardiosurgery & 32 & 4 Hours & $-1.3(7.80)$ \\
\hline Cox et al(2006) & NIV for COPD exacerbations & 22 & 4 hours & $-0.15(0.75)$ \\
\hline Cuvelier et al (2005) & Long-term home NIV & 12 & 40 minutes & $-0.72(2.98)$ \\
\hline Gancel et al (2011) & Acute resp.failure in ED & 29 & 2 hours & $0.01(0.81)$ \\
\hline Hazenburg et al (2011) & Chronic resp.failure & 15 & 8 hours & $0.40(0.87)$ \\
\hline Janssens et al (1998) & NIV in ICU & 26 & 4 hours & $0.10(0.69)$ \\
\hline Janssens et al (2001) & NIV in ICU & 28 & 8 hours & $-2.8(3.8)$ \\
\hline Johnson et al (2008) & Tracheostomised patients & 41 & 10 hours & $0.07(0.55)$ \\
\hline Kelly and Klim (2011) & Acute resp.failure in ED & 46 & Single & $0.81(1.87)$ \\
\hline Nicolini and Ferrari (2011) & Acute resp failure requiring NIV & 80 & 10 minutes & $0.11(0.73)$ \\
\hline Paiva et al (2009) & Chronic resp.failure & 65 & 6 hours & $1.00(5.20)$ \\
\hline Parker and Gibson (2007) & Routine resp.practice & 48 & 10 minutes & $-0.04(1.34)$ \\
\hline Sivan et al (1992) & Paediatric resp.failure & 134 & Single & $0.17(1.92)$ \\
\hline Storre et al (2007) & NIV titration & 10 & 4 hours & $0.61(1.15)$ \\
\hline Storre (2011) & Nocturnal NIV in chronic resp.failure & 24 & 8 hours & $0.11(1.00)$ \\
\hline
\end{tabular}

